\title{
Report of Field Activities 1991 \\ On Lands Administered By The \\ Montana Department Of Highways
}

STATE DOCUMENTS COLLECTION

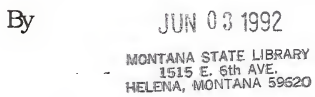

\author{
Patrick Leiggi \\ Museum of the Rockies \\ Montana State University \\ Bozeman, Montana 59717
}

\begin{abstract}
Preliminary Report on Collecting Activities Regarding Collecting Permit Authorized by the Montana Department of Highways Dated June 11, 1991
\end{abstract}

Specimens and Data Collected By Patrick Leiggi Museum of the Rockies, Montana State University

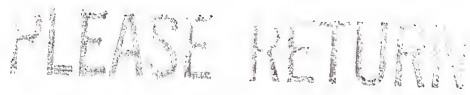


(3)

(1)

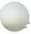




\section{ABSTRACT}

The report of a Mosasaur skull by Marilyn Wyss of the Department of Montana Highways led to the collection of an unidentified partial Mosasaurine skull. The specimen had been damaged by vandals before the site could be visited by Mr. Patrick Leiggi of the Museum of the Rockies. The site is located 3 miles north of Melstone, Montana along the west side of the Musselshell River Sec. 9, R. 30 E., T. 10 N., Musselshell Co., Montana (Fig. 1).

\section{PROJECT INTRODUCTION}

The Department of Paleontology at the Museum of the Rockies, Montana State University is dedicated to the paleontological interpretation of vertebrate life in the Northern Rocky Mountain Region. Road-cuts along Montana Highways have in the past produced remains of vertebrate fossil specimens. Investigative surveys along Montana's highways is important for the preservation of fossil specimens and the accuracy of describing scientific data.

\section{METHODS}

The collection of a partial mosasaur skull was warranted after the Museum of the Rockies received a report from Marilyn Wyss of the Montana Department of highways. Collecting was performed with small hand tools and the specimen was stabilized by traditional methods of plaster jacketing. Fragmentary material was wrapped and 
(1)

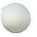

O 
bagged. No other fossil material was evident after the removal of the skull. Collecting took place on June 26, 1991.

RESULTS

Mosasaurs are common in the upper Cretaceous Bearpaw shale, although, the genus and species of this skull can not be determined until preparation of the specimen is complete. Photographs were not taken at the site. Exact geologic date can not be determined unless stratigraphic data is measured. The sole purpose of collecting this specimen was to recover the skull before further damage resulted and did not warrant the recording of stratigraphic data.

MANAGEMENT RECCOMENDATIONS

The mosasaur site and similar sites are in risk of human destruction by private and commercial collectors. Future finds should be reported to the Museum of the Rockies and kept confidential until field studies are completed. 


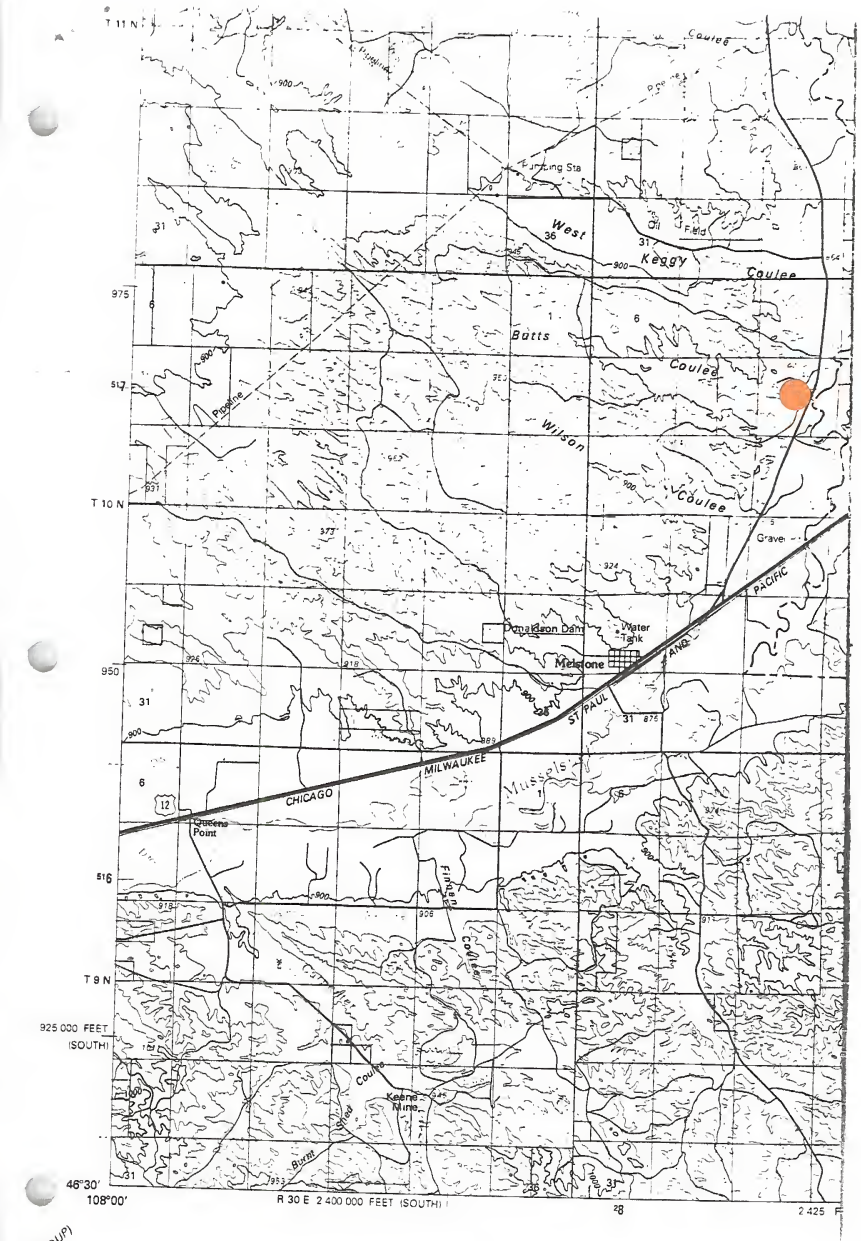

Edited and published by the Bureau of Land Management

Base map prepared by the U.S. Geological Survey

Compiled from USGS 1:24 000-scale topographic maps

dated $1960-1965$ Seen 
